\title{
Review of evaluations of educational approaches to promote safe storage of firearms
}

\author{
K S McGee, T Coyne-Beasley, R M Johnson
}

Injury Prevention 2003;9:108-111

\begin{abstract}
Objective: To systematically review evaluation studies of educational interventions promoting safe firearm storage.

Methods: Medline, ERIC, PsycINFO, Criminal Justice Periodicals Index, Cumulative Index of Nursing and Allied Health Literature, and Sociofile were searched. The references from each potentially eligible study were checked, and experts in the field were contacted for additional reports. In addition, an internet search was performed to identify programs not published in the conventional literature. Sources relevant to safe firearm storage promotion were selected and evaluated. Results: Seven studies met inclusion criteria: adult subjects, program description was included, and firearm storage outcomes were measured. One was a randomized controlled trial and the other six were one group pre-test and/or post-test. The studies were classified into the following categories based on the intervention strategies used: (1) counseling and firearm safety materials $(n=3) ;(2)$ counseling/educational message $(n=3)$; and (3) firearm safety materials distribution $(n=1)$. The outcomes were safe firearms storage (firearms locked up and unloaded or removal from home) after intervention. Four studies, three using counseling and materials distribution, reported improved storage after the interventions.

Conclusions: It is not yet clear what types of interventions, or which specific intervention components, prompt gun owners to securely store their weapons. Increased understanding of gun storage behaviors and stronger evaluation designs will aid further understanding of this important issue.
\end{abstract}

See end of article for authors' affiliations

Karra S McGee

Health Organization,

Department of Injuries and

Violence Prevention

NMH/VIP, 20 Avenue

Appia, $\mathrm{CH}-1211$ Geneva

27. Switzerland

mcgeek@who.int

$\mathrm{F}$ rearm related injuries are a serious problem in the United States. In 2000, 672 children (ages 0-15) were killed and an additional 4845 were seriously injured from firearm gunshots. ${ }^{1}$ The fact that US youth have considerable access to firearms in their homes ${ }^{2-4}$ likely contributes to the firearm injury problem..$^{5-7}$ Over one third of households with children contain firearms, and in about $10 \%$ of those homes firearms are stored both loaded and unlocked. ${ }^{489}$ It follows, then, that reducing youth access to firearms through certain storage practices is an important strategy for injury prevention. ${ }^{10}$ The American Academy of Pediatrics, the American Medical Association, the American Academy of Family Physicians, and the United States Preventive Services Task Force support safe firearm storage in homes with youth. ${ }^{11}$

Safe firearm storage promotion programs take place in clinical and community settings, and primarily rely on educational messages, free or discounted gunlock distribution, or a combination of the two to encourage parents to lock up and unload household firearms. ${ }^{12}$ The degree to which such programs are successful at eliciting behavior change is unclear. In this paper we systematically review safe firearm storage promotion programs to assess their overall effectiveness.

\section{METHODS}

In order to be included in this review, intervention studies had to meet the following criteria: (1) the program was targeted to a defined adult population; (2) a description of the intervention was available; and (3) outcomes, including storing firearms unloaded, locked up in a lock box, gun safe, secured with a trigger or gunlock, or removal of firearm(s) from the home, were measured. Studies were further limited to US settings and English language publications.

In order to identify studies, using the keywords "firearms" and "safety", the following electronic databases were searched in August 2001 for the period indicated: Medline (19662001), ERIC (1966-2001), PsycINFO (1966-2001), Criminal Justice Periodicals Index (1990-2001), Cumulative Index of Nursing and Allied Health Literature (1982-2001), and Sociofile (1974-2001). Additionally, the reference lists of the identified documents were searched for eligible programs. In order to identify literature not published in scientific journals, an internet search was performed. Using the search engine "Google" we did an exact phrase search for "safe firearm storage". Once programs were identified on the internet, a staff member was interviewed via telephone to obtain further information.

\section{RESULTS}

Seven studies met inclusion criteria. Three other studies were identified during the literature search but were not included because there was not an evaluation component in the programs. Six programs were identified through the internet search. Telephone interviews with program administrators revealed that no evaluation has been completed, therefore, these programs were not included in the review. The studies were classified into the following categories based on the intervention strategies used: (1) counseling and materials distribution $(\mathrm{n}=3)^{13-15} ;(2)$ counseling/educational message $(\mathrm{n}=3)^{16-18}$; and (3) materials distribution $(n=1) .{ }^{19}$ Counseling/educational message programs were characterized by provision of information about the dangers of having a gun in the home and the importance of either removing guns from the home, or storing them unloaded and locked up. Materials distribution programs included dissemination of gun safety devices only. Counseling and materials distribution interventions entailed both dissemination of firearm safety information and distribution of either a safe storage device, ${ }^{14}{ }^{15}$ or a safe storage device coupon. ${ }^{13}$ Results are summarized in table 1. 
Table 1 Characteristics and results of studies promoting safe firearm storage

\begin{tabular}{|c|c|c|c|c|c|}
\hline Investigators & $\begin{array}{l}\text { Study } \\
\text { design }\end{array}$ & Sample & Intervention & Outcome & Results \\
\hline $\begin{array}{l}\text { Grossman et al } \\
(2000)^{13}\end{array}$ & $\begin{array}{l}\text { Randomized } \\
\text { controlled } \\
\text { trial }\end{array}$ & $\begin{array}{l}\text { Families visiting a staff } \\
\text { model health } \\
\text { maintenance } \\
\text { organization in } \\
\text { Washington }(n=1295)\end{array}$ & $\begin{array}{l}\text { Control group } \rightarrow \text { usual practice } \\
\text { Intervention group without gun } \\
\rightarrow \text { counseling and pamphlet } \\
\text { Intervention group with gun } \rightarrow \\
\text { counseling, safe storage } \\
\text { information packet, and } \\
\text { storage device coupon }\end{array}$ & $\begin{array}{l}\text { Changes in self reported } \\
\text { events: ( } 1 \text { ) acquisition of } \\
\text { safe storage device, (2) } \\
\text { removal of gun from home, } \\
\text { and (3) acquisition of guns }\end{array}$ & $\begin{array}{l}\text { No significant differences between } \\
\text { intervention and control groups in: } \\
\text { (1) rate of acquisition of new guns } \\
\text { (2) removal of guns }\end{array}$ \\
\hline $\begin{array}{l}\text { Coyne-Beasley et } \\
\text { al }(2001)^{14}\end{array}$ & $\begin{array}{l}\text { One group, } \\
\text { before and } \\
\text { after }\end{array}$ & $\begin{array}{l}\text { Adult gun owners in } \\
\text { North Carolina }(n=112)\end{array}$ & $\begin{array}{l}\text { Tailored education message by } \\
\text { health professional, gun safety } \\
\text { information packet, and free } \\
\text { cable gun lock distribution }\end{array}$ & $\begin{array}{l}\text { Self reported firearm } \\
\text { storage practices }\end{array}$ & $\begin{array}{l}\text { (1) Those who stored gun a locked } \\
\text { compartment increased }(p<0.05) \\
\text { (2) Those who reported using gun } \\
\text { locks increased ( } p<0.05) \\
\text { (3) Participants with children were } \\
\text { more likely to store gun safely after } \\
\text { counseling }(p<0.05)\end{array}$ \\
\hline Horn $(1999)^{15}$ & $\begin{array}{l}\text { One group, } \\
\text { before and } \\
\text { after }\end{array}$ & $\begin{array}{l}\text { Adult gun owners in } \\
\text { Alaska }(n=40)\end{array}$ & $\begin{array}{l}\text { Distribution of } 1 \text { gun safe and } \\
1 \text { trigger lock per household in } \\
\text { association with safety } \\
\text { message }\end{array}$ & $\begin{array}{l}\text { Firearm storage practices } \\
\text { assessed at unannounced } \\
\text { home visit with visual } \\
\text { inspection by author }\end{array}$ & $\begin{array}{l}\text { (1) } 78 \% \text { ( } 29 \text { of } 37 \text { ) of participants } \\
\text { were using the gun safe correctly to } \\
\text { store firearms } \\
\text { (2) } 30 \% \text { of trigger locks were being } \\
\text { utilized by participants }\end{array}$ \\
\hline $\begin{array}{l}\text { Brent et al } \\
(2000)^{16}\end{array}$ & $\begin{array}{l}\text { One group, } \\
\text { before and } \\
\text { after }\end{array}$ & $\begin{array}{l}\text { Parents of adolescents } \\
\text { with major depression } \\
\text { in Pennsylvania }(n=106)\end{array}$ & $\begin{array}{l}\text { Education message about the } \\
\text { risk of firearms in home and } \\
\text { recommendations for removal } \\
\text { and safe storage }\end{array}$ & $\begin{array}{l}\text { Rates of gun removal and } \\
\text { gun acquisition }\end{array}$ & $\begin{array}{l}\text { (1) Of those who had guns at } \\
\text { intake, } 26.9 \% \text { reported removing } \\
\text { them by the end of the acute trial } \\
\text { (2) Of those who did not have guns } \\
\text { at intake, } 17.1 \% \text { reported acquiring } \\
\text { them over } 2 \text { year follow up }\end{array}$ \\
\hline $\begin{array}{l}\text { Oatis et al } \\
(1999)^{17}\end{array}$ & $\begin{array}{l}\text { One group, } \\
\text { before and } \\
\text { after }\end{array}$ & $\begin{array}{l}\text { Parents of pediatric } \\
\text { patients at an urban } \\
\text { pediatric practice in the } \\
\text { Midwest ( } n=1617 \text { ) }\end{array}$ & $\begin{array}{l}\text { Educational message based on } \\
\text { STOP program of the American } \\
\text { Academy of Pediatrics }\end{array}$ & $\begin{array}{l}\text { Self reported change in } \\
\text { gun ownership and firearm } \\
\text { storage methods }\end{array}$ & $\begin{array}{l}\text { (1) Gun ownership decreased after } \\
\text { the intervention }(p=0.1) \\
\text { (2) Handgun ownership decreased } \\
(p=0.1) \\
\text { (3) Long gun ownership decreased } \\
(p=0.8) \\
\text { (4) Storing gun outside of a locked } \\
\text { container did not change }(p=1.0) \\
\text { (5) Keeping any gun loaded } \\
\text { decreased }(p=0.3)\end{array}$ \\
\hline $\begin{array}{l}\text { Kruesi et al } \\
{(1999)^{18}}\end{array}$ & $\begin{array}{l}\text { One group, } \\
\text { after only }\end{array}$ & $\begin{array}{l}\text { Adults whose children } \\
\text { made an emergency } \\
\text { department visit for } \\
\text { mental health } \\
\text { assessment at a rural } \\
\text { Midwestern hospital } \\
\text { ( } \mathrm{n}=103 \text { ) }\end{array}$ & $\begin{array}{l}\text { Means restricted education to } \\
\text { limit youth access to lethal } \\
\text { means for suicide }\end{array}$ & $\begin{array}{l}\text { Self report of caretaker } \\
\text { action to limit access to } \\
\text { gun, that is, locking gun in } \\
\text { a locked compartment or } \\
\text { with trigger lock, or } \\
\text { removing gun from the } \\
\text { home }\end{array}$ & $\begin{array}{l}\text { (1) } 5 \text { of } 8 \text { adults who had firearm in } \\
\text { home took action to limit access } \\
(p \leqslant 0.05) \\
\text { (2) } 2 \text { of } 8 \text { disposed of the gun } \\
(p \leqslant 0.05) \\
(3) 3 \text { of } 8 \text { locked up the gun } \\
(p \leqslant 0.05)\end{array}$ \\
\hline $\begin{array}{l}\text { Coyne-Beasley } \\
\text { and Johnson } \\
(2001)^{19}\end{array}$ & $\begin{array}{l}\text { One group, } \\
\text { after only }\end{array}$ & $\begin{array}{l}\text { Law enforcement } \\
\text { officers in the South } \\
\text { ( } n=103 \text { ) }\end{array}$ & Free keyed cable gun locks & $\begin{array}{l}\text { Self reported use of gun } \\
\text { lock }\end{array}$ & $\begin{array}{l}65 \% \text { reported they were not using } \\
\text { the gun lock they collected }\end{array}$ \\
\hline
\end{tabular}

\section{Counseling and materials distribution interventions} Only one study using the counseling and materials distribution intervention strategy was a randomized controlled trial. Grossman et al targeted families visiting a physician's office. ${ }^{13}$ If gun ownership was reported, those in the intervention group were given counseling, safe storage information, and a coupon to purchase an extrinsic safety device. Those who did not own guns were given counseling and a pamphlet. Control group participants received usual care. Outcomes included self report of acquisition of safe storage devices, removal of guns from the home, and acquisition of guns. There were no differences between intervention and control group participants with respect to gun acquisition and removal of guns from the home. Only $8 \%$ of the intervention group purchased a trigger lock.

Coyne-Beasley et al conducted a community based intervention targeting adult gun owners in North Carolina. ${ }^{14}$ Participants received a tailored educational message delivered by a health professional, gun safety information, and a free keyed cable gun lock. Law enforcement officers instructed participants on how to secure the lock on their particular firearm.
Self report surveys before and after intervention were conducted. Outcomes measured were: number of gun(s) locked up in a compartment and/or unloaded, whether ammunition was locked up and stored separately from guns, and gun lock use. Statistically significant findings included an increase in the percentage of those who were using gun locks and storing guns in a locked compartment.

Horn conducted a community based program targeting randomly selected adult gun owners in two rural towns in Alaska. ${ }^{15}$ Participants received a gun safe and trigger lock along with a safety message. The outcomes measured, use of the gun safe and/or trigger lock, were assessed during an unannounced home visit with visual inspection. On follow up, $78 \%$ of the participants were using the gun safe and $30 \%$ of the participants were using trigger locks.

\section{Counseling/educational message interventions}

Three studies utilized the counseling/educational message intervention strategy. ${ }^{16-18}$ Brent et al targeted parents whose adolescents were suffering from major depression and were participating in a randomized clinical psychotherapy trial. ${ }^{16}$ 
During the intake interview, parents with a gun in the home received an educational message about the risk of firearms in the home and were given recommendations for removal and safe storage of firearms. The outcomes measured were self report of gun removal and gun acquisition. Of those who had guns at intake, $27 \%$ reported removing them from the home ${ }^{16}$ Unfortunately, $17 \%$ of those who did not own a gun at baseline acquired one over the two year follow up period.

Oatis et al conducted an intervention at a pediatric clinic targeting patients' parents. ${ }^{17}$ Parents received an educational message based on the STOP program ${ }^{20}$ of the American Academy of Pediatrics which encourages removal of guns from the home, and if removal is not considered an acceptable option, storing guns unloaded and locked up. Outcomes measured were self reported change in gun ownership and firearm storage. There were no statistically significant changes in firearm ownership or storage practices.

Kruesi and colleagues targeted adults whose children were being seen at an emergency department for a mental health assessment. ${ }^{18}$ Parents received an educational message about limiting youth access to firearms and other lethal means for suicide. The outcomes measured were storing guns in a locked compartment or with a trigger lock, and removing guns from the home. The study found a significant association between exposure to the intervention and behavior change.

\section{Materials distribution interventions}

Only one study used the material distribution intervention strategy. Coyne-Beasley and Johnson distributed free keyed cable gun locks to law enforcement officers who wanted one. ${ }^{19}$ The outcome of interest, use of the device, was measured via anonymous self report. The majority $(65 \%)$ reported that they were not using the gun lock. The primary reason given for not using the gun locks was a perceived inability to access firearms quickly in case of an emergency or home invasion.

\section{DISCUSSION}

Reducing access to household firearms through safe storage could reduce the number of firearm injuries to youth, especially unintentional injury and suicides. Educating the public is a strategy for changing firearm storage practices. ${ }^{12}$ Therefore, in this review we examined the effectiveness of safe firearm storage promotion programs. After an extensive search, we found only seven such programs that had been evaluated. Unfortunately, there is little evidence that those programs are effective at eliciting behavior change (table 1).

The easy conclusion to draw is that evaluations of safe firearm storage promotion programs have a multitude of methodological problems, including weak study designs, potentially biased sampling procedures, and small sample sizes (table 1). Only one of the seven studies employed a randomized controlled trial design. ${ }^{13}$ Most of the studies included in this review are one group, pre-test/post-test designs, which makes it difficult to draw solid conclusions about their success. Most outcomes were measured via a self reported survey of participants at some time period before and after intervention; therefore, reporting bias is possible. Some of the programs collected data in a clinical setting so some participants might misreport firearm storage methods or there may be a tendency to conceal unsafe practices in aiming to give a socially desirable response. Some of the studies reviewed here also report positive changes in firearm storage practices after intervention but failed to test for statistical significance of these findings. ${ }^{15} 16$

There are clear shortcomings in the methodological quality of the evaluation studies of safe firearm storage promotion programs. However, we would be remiss if our only conclusion was that these programs have not been established as being effective only because they have not had rigorous enough evaluations. When a given intervention strategy is working, inklings of success often shine through despite the weakest methods. Additionally, even the strongest studies in this review produced null results. ${ }^{13}$ Thus, it is likely that the approach of safe storage promotion programs needs to be re-examined.

Nevertheless, there are some lessons to be learned from unique components of the interventions reviewed here. For example, the "Love Our Kids, Lock Your Guns" program was preceded by a multimedia campaign and included a counseling session and demonstration of the use of the safety device that was provided to participants. ${ }^{14}$ In addition, participants self selected into the program and therefore, may have been motivated to change their storage behaviors. The program evaluated by Horn was unique because in addition to including an educational message and providing safety devices, the intervention took place in the homes of participants, focus groups were utilized to identify gun owners' attitudes and preferences, and the outcome was measured via an unannounced home visit to assess safety device usage. ${ }^{15}$ These unique aspects may have influenced the finding that $78 \%$ of participants were using the gun safe at follow up.

\section{Limitations}

There were six safe storage promotion programs identified during the internet search that have not been evaluated or are in the process of being evaluated. For example, the National Shooting Sports Foundation's "Project HomeSafe" has distributed over 400000 free gun locks in recent years, ${ }^{21}$ but an evaluation of the program has not been completed (personal communication, Dee Dee Sarff, 7 June 2001). Similarly, the US Department of Justice, the Ad Council and the National Crime Prevention Council's "Unload and Lock" nationwide, multimedia public service advertising campaign has no plans for program evaluation. ${ }^{22}$ Additionally, the Harborview Injury Prevention and Research Center in Seattle, Washington is conducting a case-control study of a safe gun storage campaign promoting the sale and use of handgun lock boxes. ${ }^{23}$ Evaluation of the program via random digit dial telephone survey is currently being conducted (personal communication, LuAnn D'Ambrosio, 16 May 2001). These programs may show some effectiveness in changing firearm storage behaviors, but without completed evaluations we have no information about the degree to which they are worthwhile. Additionally, among those safe firearm storage promotion programs that have been evaluated, many are not available in the peer reviewed academic literature, making it difficult to identify and include them in this review. Therefore, we would like to call for increased evaluation, better evaluation, and greater visibility of completed evaluations for safe firearm storage promotion programs. This will aid greatly in planning and designing future programs.

\section{Recommendations for future research}

While some of the studies reviewed here offer some evidence that safe firearm storage promotion programs are effective in improving storage practices, improved methodologies for future interventions will lead to clearer answers. Following is a list of potential improvements:

- Use of control groups to account for such things as the effect of self selection or phenomenon that may occur during the study period.

- Measure outcomes such as injury incidence as well as behavior.

- Measure outcomes objectively when possible.

- Use statistical tests to compare changes in pre-tests and post-tests.

Additionally, program designers need to build evaluations into their program plans and completed programs should consider 


\section{Key points}

- Firearm related injuries are a serious problem in the US

- US youth having access to firearms in their homes likely contributes to the firearm injury problem.

- Reducing youth access to firearms through certain storage practices is an important strategy for injury prevention.

- The degree to which safe firearm storage promotion programs are successful is unclear.

- This review of safe firearm storage promotion programs suggests that there is little evidence that these programs are effective at eliciting improved firearm storage behaviors.

- Improved methodologies for future interventions are needed and will lead to clearer answers about what prompts gun owners to securely store their firearms.

conducting evaluations, especially where large scale gun lock distributions have taken place. However, there are still some unresolved issues to consider in designing safe firearm storage promotion programs and these should be considered in future research. Issues of particular importance for firearm safety counseling are the content and delivery of the safety message: what messages are most effective, what should be said, who should deliver the message, how it should be delivered, and who is the best person to receive the safety message. In addition, many programs distributed safety devices that have not been formally tested. Program planners should consider that there have been no published evaluations of gun and trigger locks, which vary considerably in quality; indeed some locks have been recalled due to malfunction. Furthermore, thought should be given to the fact that some safety devices, such as lock boxes or gun safes, are preferred and may prompt safer storage practices. Finally, there are several studies that show that gun owners who have received firearm safety training are either more likely ${ }^{24}{ }^{25}$ or neither more nor less likely ${ }^{26}{ }^{27}$ to store their firearms loaded and unlocked. These findings are relevant in designing and evaluating educational approaches to safe firearm storage.

\section{CONCLUSIONS}

Based on the findings in this review we are at the early stages of understanding what types of interventions, or which components of interventions, prompt gun owners to securely store their firearms. Improved understanding of attitudes, beliefs, gun storage behaviors, improved study design and consideration of evaluation methods in program planning will aid further understanding of this important issue.

\section{ACKNOWLEDGEMENTS}

We thank Carol Runyan and Carolyn Halpern for their comments on early drafts of this paper.

\section{Authors' affiliations}

K S McGee, Department of Maternal and Child Health, University of North Carolina at Chapel Hill, School of Public Health, Chapel Hill, North Carolina

T Coyne-Beasley, Department of Pediatrics and Internal Medicine, University of North Carolina at Chapel Hill, School of Medicine, and University of North Carolina Injury Prevention Research Center, Chapel Hill, North Carolina

R M Johnson, Department of Health Behavior and Health Education, School of Public Health, University of North Carolina at Chapel Hill, Chapel Hill, North Carolina

\section{REFERENCES}

1 Centers for Disease Control and Prevention, National Center for Injury Prevention and Control. Web-based injury statistics query and reporting system. Available at: http://www.cdc.gov/ncipc/wisqars/ default.htm (accessed 28 May 2002).

2 Swahn MH, Hamming BJ, Ikeda RM. Prevalence of youth access to alcohol or a gun in the home. Inj Prev 2002;8:227-30.

3 Cook PJ, Ludwig J. Guns in America: results of a comprehensive national survey on firearm ownership and use. Summary report. Washington, DC: Police Foundation, 1996.

4 Schuster MA, Franke TM, Bastian AM, et al. Firearm storage patterns in US homes with children. Am J Public Health 2000;90:588-93.

5 Grossman DC, Reay DT, Baker SA. Self-inflicted and unintentional firearm injuries among children and adolescents: the source of the firearm. Arch Pediatr Adolesc Med 1999;153:875-8.

6 Brent DA, Perper JA, Allman CJ, et al. The presence and accessibility of firearms in the homes of adolescent suicides-a case-control study. JAMA 1991;266:2989-95.

7 Powell EC, Jovtis E, Tanz RR. Incididence and circumstances of nonfatal firearm-related injuries among children and adolescents. Arch Pediatr Adolesc Med 2001:155:1364-8.

8 Hemenway D, Solnick SJ, Azrael DR. Firearm training and storage. JAMA 1995;273:46-50.

9 Stennies G, Ikeda R, Ledbetter S, et al. Firearm storage practices and children in the home, United States, 1994. Arch Pediatr Adolesc Med 1999; 153:585-90.

10 United States General Accounting Office. Accidental shootings: many deaths and injuries caused by firearms could be prevented. Washington, DC: US GAO, 1991

11 Quinlan KP, Sacks JJ, Kresnow M. Exposure to and compliance with pediatric injury prevention counseling-United States, 1994. Pediatrics 1998;102:1-4.

12 Hardy MS. Behavior-oriented approaches to reducing youth gun violence. The Future of Children 2002;12:101-18.

13 Grossman P, Cummings, DC, Koepsell TD, et al. Firearm safety counseling in primary care pediatrics: a randomized, controlled trial. Pediatrics 2000;106:22-6.

14 Coyne-Beasley T, Schoenbach VJ, Johnson, RM. Love our kids, lock your guns: a community-based firearm safety counseling and gun lock distribution program. Arch Pediatr Adolesc Med 2001;155:659-64.

15 Horn A. Suicide analysis among Bristol Bay residents 1993-1999 and distribution of gun safety devices in two Bristol Bay communities. Bristol Bay Area Health Corporation, Dillingham, AK: Indian Health Services, United States Public Health Service, 1999.

16 Brent DA, Baugher M, Birmaher B, et al. Compliance with recommendations to remove firearms in families participating in a clinical trial for adolescent depression. J Am Acad Child Adolesc Psychiatry 2000;39:1220-5

17 Oatis PJ, Fenn-Buderer NM, Fleitz R. Pediatric practice based evaluation of the Steps to Prevent Firearm Injury program. Inj Prev 1999:5:48-52.

18 Kruesi MJ, Grossman J, Pennington JM, et al. Suicide and violence prevention: parent education in the emergency department. J Am Acad Child Adolesc Psychiatry 1999;38:250-5.

19 Coyne-Beasley T, Johnson RM. Law enforcement officers' opinions about gun locks: anchors on life jackets. Inj Prev 2001;7:200-4

20 American Academy of Pediatrics, Center to Prevent Handgun Violence. STOP: steps to prevent firearm injury. Elk Grove Village, IL: American Academy of Pediatrics, Center to Prevent Handgun Violence, 1994.

21 Project Homesafe. Participating cities. Available at http:// www projecthomesafe.org/participants. htm (accessed 22 June 2001).

22 National Crime Prevention Council. Gun violence prevention through safe storage. Funding Proposal submitted to Bureau of Justice Assistance US Department of Justice, 4 May 2001.

23 Harborview Injury Prevention and Research Center. The Safe Storage Campaign, a program of the Harborview Injury Prevention and Research Center, Seattle Washington. Available at http://depts. washington.edu/hiprc/SafeStorage.overview.pdf (accessed 3 May 2001)

24 Hemenway D, Solnick SJ, Azrael DR. Firearm training and storage. JAMA 1995:273:46-50.

25 Nordstrom DL, Zwerling C, Stromquist AM, et al. Rural population survey of behavioral and demographic risk factors for loaded firearms. Inj Prev 2001;7:112-16.

26 Weil DS, Hemenway D. Loaded guns in the home-analysis of a national random survey of gun owners. JAMA 1992;267:3033-7.

27 Cook PJ, Ludwig J. Guns in America: National survey on private ownership and use of firearms. Washington, DC: US Department of Justice, National Institute of Justice, 1997 